\title{
Examining the Accessibility, Support, Benefits of Training in Road and Transport Authority: The Case of Service Quality in UAE
}

\author{
Hamdan ALMATRUSHI, Mohammed NUSARI, Ali Ameen, Amiya Bhaumik
}

\begin{abstract}
This study investigates the relationships between three training dimensions and affective organizational commitments, as well as service quality within $U A E$ public sectors. In the current study, the relation between the access, support, and benefits of training are assessed by implementing affective organizational commitment as their mediating . The study was conducted using survey research design with 540 participants of UAE licenced units. Analysis of the confirmatory parameters were conducted to demonstrate the quality services of the three licenced units of the training scales and hypothesis testing were conducted. The study findings showed that all the dimensions of the training directly and indirectly positively affected service quality of $U A E$ public sectors. In addition to that, the three-training dimension have also a positive effect on affective organizational commitments. Further affective organizational commitment positively affected service quality.
\end{abstract}

Keywords : Access, support, and benefits of training, affective organizational commitment, service quality, public sectors, UAE.

\section{INTRODUCTION}

$\mathrm{P}$ ublic transportation is one of the important services provided for the denizens of the societies and countries. Hence, they need effective public transport services. Public transportation is defined as transportation by a conveyance that provides continuing general or special transportation to the public. More focus should be given to the social and environmental aspects instead of just economical benefits.. Varied countries are encountering with issues because of the rapid increase in the ownership of the private automobiles. Some of the reasons include inefficient public transport and weakening urban environment.. However, to maintain a decorum among the drivers, certain norms are bound to followed, including regular schedules, high service quality, efficient usage of the resources.

Previous studies of public transport sustainability in cities have been very limited to date, particularly in more developing countries located throughout Asia and the Middle

Revised Manuscript Received on September 22, 2019.

Hamdan ALMATRUSHI, Faculty of Business and Accountancy, Lincoln University College, Selangor, Malaysia

Mohammed NUSARI, Faculty of Business and Accountancy, Lincoln University College, Selangor, Malaysia

Ali Ameen, Faculty of Business and Accountancy, Lincoln University College, Selangor, Malaysia

Amiya Bhaumik, Faculty of Business and Accountancy, Lincoln University College, Selangor, Malaysia
East. Despite the advantages of public transportation, the concept is still not popular in the Middle East, particularly within the Gulf Cooperative Council (GCC) countries. However, the need to strengthen public transportation systems recently gained new momentum in the Middle East. In the Middle East and North Africa (MENA) region, the Congress gave more stress on formulating long-term striving plans intended to expand and upgrade the public transport sectors. In MENA countries, major gaps are evident in the capacity if the urban and rural transport infrastructure Addressing these gaps and briding them can accelerate the economic growth and other parameters of these regions . Some of the GCC countries have initiated to boost the economy by implementing regulation, competition, and growth in employment.

Service quality has been as part of a customer's desired expectation of service and is considered the difference between customer expectations and the kind of service the customer receives; if the latter does not meet the level of satisfaction, it leads to a feeling of discontentment on the part of customers. Such services focus more on providing a safe, efficient, and economic transport to the consumers by formulating impactful and cost-effective measures. Studies have supported it by concluding that they benefit the society by making the traffic less congested, saving money, and creating long-run jobs. Improvements in the public transportation links between urban and suburban areas result in a shift in the population from urban to suburban areas. However, providing training in service quality specially in hospitality in which quality of services has been the most important characteristic of a company could differentiate it from its competitors in similar industries.

Organizational literature has examined the relationship between organizational commitment and a variety of organizational behaviours. In the private sector, for instance, the significant relationship between managerial commitment and quality of service have been reported. This study investigates the effects of organizational commitment on training for road and transport service quality. The impact of perceived accessibility to training, the impact of perceived support of training, and the impact of perceived benefits of training on affective organizational commitment of services quality in UAE are considered. The rest of the paper is organized as follows: section 2 below reviews the literature, the methodological process is 
presented in section 3 Section 4 presents the empirical results and analyses. Finally, the conclusions with limitations of research of the study and some recommendations are provided in section 5 .

\section{Literature REVIEW}

\section{A. Organizational Commitment}

Organizational commitment is defined as "the relative strength of an individual's identification with and involvement in a particular organization". It has sparked as widespread interest in the field of organizational behaviour. Furthermore, it has been considered as a multidimensional construct including three module, i.e. affective, continuance, and normative commitment. Affective organizational commitment on the other hand has been seen as emotional attachment to, identification with and involvement in the organization of an employee. According to research works, affective organisational commitment, which refers to a psychological attachment to, and involvement with, an employing institution, is regarded as important because of its effects on employee identification with the employer and its causal effects on work effort and staff retention.

Employees with a strong and effective organizational commitment should continue their employment with the organization. In their definition of organizational commitment, researchers characterized affective commitment as entailing "a strong belief in and acceptance of the organization's goals and values, a willingness to exert considerable effort on behalf of the organization, and a strong desire to maintain membership in the organization". Affective commitment or feelings of belonging and sense of attachment to the organization happens when the employee has an emotional attachment with the organization.

The affective commitment dimension has been related to personal characteristics, organizational structures, and work experiences (pay, supervision, role clarity, and skill variety). Individuals whose organizational commitment is based on affective commitment continue employment with the organization because of their desire to do so; this desire is based on the individual's degree of identification with the organization and their willingness to assist the organization in pursuing its goals. It has been suggested that organizations enhance affective commitment by "improving welfare measures, developing trust between superiors and subordinates, creating conditions for collegial relations in the work place, and other activities that promote feelings of belongingness in the organization.".

The long-term health and success of any organization depends upon the retention of key employees. As a result, Human Resource Management Strategy (HRMS) try to prevent the employee turnover by implementing effective retention strategies. Effective retention management requires ongoing diagnosis of the nature and causes of turnover, a strategic approach to determining in what human capital markets retention has the largest impact on organizational success, and the development of an appropriately targeted and organized bundle of retention initiatives. Employee retention is a process in which the employees are encouraged to remain with the organization for the maximum period. Retention has been defined as "customer liking, identification, commitment, trust, readiness to recommend, and repurchase intentions, with the first four being emotional-cognitive retention constructs, and the last two being behavioural intentions. In this era of development, where technology changes every now and then, training becomes the prerequisite for every organization to remain in the global market. Training is defined "as the planned intervention that is designed to enhance the determinants of individual job performance. Organizational training is conceptualized within a multidimensional framework consisting of motivation for training, access to training, benefits from training and support for training.

In terms of affective organization commitment and perceived accessibility to training, access to training is denoted by the perception of the employees of an organization about the opportunities provided by the training programs. Regardless of eligibility, the employees require support from their managers in getting a fair chance to be selected for this program. This selection process also influences the relationship with the organization in terms of commitment. . It has been revealed that firms who are perceived to have fair accessibility to training programs are more likely to have a greater number of committed employees in their organization..

When the employees apprehend that their attendance in such programs will eventually their organization as well as themselves, they show more interest in attending them.. the main characteristics of a training programme that stimulate training motivation are option to voluntary attendance, training reputation, appropriate training design, and the relevance of training for job-, career-, and personal-related needs . it has been found that organizational commitment is an intangible result of training programs conducted for employees.

According to previous studies training program benefits can be looked at from three different perspectives: (a) personal benefits, (b) job related benefits, and (c) career benefits. Training refers to a plan effort by a company to facilitate the learning of specific knowledge skills or behaviours that employees need to be successful in their current job.

When the staff members realize that the training programs will affect them in a positive manner in their professional life, they show more interest in attending them. Further, previous research works have concluded that there is a strong bonding between the organizational training programs and affective commitment. The findings suggest that there is a positive relationship between employees' beliefs regarding training benefits and employees' organizational commitment.

Various studies training program do have an impact on the employee's motivation level as a result of which many researchers have categorized them under various types of motivational programs. 
Consequently, a vague explanation on the effect of the training programme on training motivation is demonstrated. In a relationship between organizational commitment and training a sample of the numerous possible antecedents that have been explored include perception, and benefits such as career, job related, personnel satisfaction; self-efficacy; social support; facilities, materials and equipment .

In terms of affective organization commitment and perceived support for training, in affective commitment employee's attachment and loyalty with their work and with their manager and supervisors, in affective organizational commitment employee always think and react positive towards their organization in any situation. Experiences of the way officers are managed were found to have the strongest influence on their organizational commitment while job related variables were found to have a lesser influence. According to previous studies supportive cultures have positive effects on commitment. Researchers using organizational commitment as a moderator of the effect of training on service performance revealed that perceived support for training has impacted organizational commitment.

When employees feel that the organization is working in the direction of upgrading their skill for the better results of both the employee and the organization, they show their obligation through their hard and result-oriented work. . In his study of "the relationship between training and organizational commitment: A study in the health care field" found a direct relationship between support for training and employee with the levels of affective commitment. For example, an earlier study showed that the effects of personality, climate, and age on training outcomes were only partially mediated by self-efficacy, valence, and job involvement. However, in more recent result of their study of "an examination of the relationship between training comprehensiveness and organizational commitment: further exploration of training perceptions and employee attitudes of human resource development quarterly" found supporting evidence for a direct relationship between perceived training comprehensiveness and organizational commitment.

In almost all cases, access to, and support for, as well as benefits of training are the most important components of organizational commitment. For example, the results of the study of revealed that all dimensions of training positively affected employee commitment. Results of more recent study showed that perceived access to training, supervisory support for training, motivation to learn from training and perceived benefits of training to have been positively related to the affective and normative components of organizational commitment. Therefore, the following hypothesis are formulated.

H1: Support for training positively affect affective organizational commitment

$\mathrm{H} 2$ : Access to training positively affects affective organizational commitment

H3: Benefits from training positively affects affective organizational commitment

H4: Support for training positively affects service quality
H5: Accessibility to training positively affects service quality

H6: Benefits from training positively affects service quality. H7: Affective organizational commitment positively affects service quality

H8: Affective organizational commitment affects the relationship between perceived support for training and service quality

H9: Affective organizational commitment affects the relationship between previewed access to training and service quality

H10: Affective organizational commitment affects the relationship between perceived benefits from training and service quality

\section{RESEARCH METHOD}

The research of this had been conducted within UAE public sectors in which, the participants had voluntarily participated. There were two types of survey methodologies: survey 1 and survey 2 . In survey 1 , the researcher distributed 540 questionnaires consisting of questionnaires regarding of employees training procedures and affective organizational commitments for front line employees who directly deal with customers. in survey 2, 1620 questionnaires were distributed consisting of questionnaires regarding service quality with ratio of 1 employee to 3 customers in 18 licensed units. The questionnaires had been distributed for those licensed units located in different departments. Each licensed unit could approximately have 30 front line employees. All the front-line employees in those units were participated in the survey. The total employees surveyed in those 18 licensed units had been 540 questionnaires. Further, all the employees had been given one week to fill the forms of the survey and submit them to the researcher personally.

In the next week, the researcher selected randomly 3 customers in different periods and days. in the first day, after the first working hour, one customer was selected for the survey and time was given him to evaluate the quality of service provided to him. In the second day, different customer was selected for the survey after the second working hour. Finally, In the third day of the survey processes, the different customer was selected for survey after the three-working hour and time was given to him to evaluate the types of service provided to him to study the quality of services across those licensed units. The total customers participated in each unit were 90 in three days, thus, the total number in 18 units was 1620 .

The valid employee questionnaires returned are 505 (93.5\%) out of 540 and the valid customers' questionnaires returned are $1263(78 \%)$ out of 1620 . On this representative sample, the survey was carried out to find out the extent of the three dimensions of employee training (access to training, support for training and benefits from training) could have affected affective organizational commitments of employees and the perceptions of customers of the types of services provided in those units the understand the nature of the service quality UAE. These types of surveys in fact helps understand the mediating role of AOC between the three dimensions of employee training and service quality. The

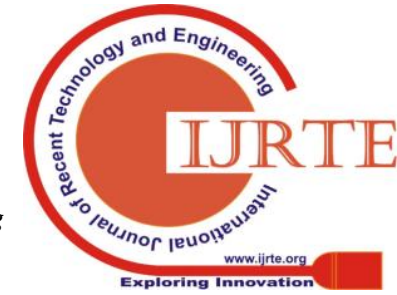


measurements of the items for the different perceived trainings and affective organizational commitment, for the survey were based on a 7-point Likert-type scale, except the measurement of the items for the service quality which was based on a 5-point-type scale.

As what has just been seen, the responding sample for the total surveys were 1,768 observation $(n=1,768)$ consisting of
$44.6 \%$ males and $56.4 \%$ female. Table 3.1 below shows the details of the demographic factors of the current study including gender, age, education, and tenure of employees. In addition, the proposed model can be seen in figure 3.1 below

Table 3.1: Demographic Details

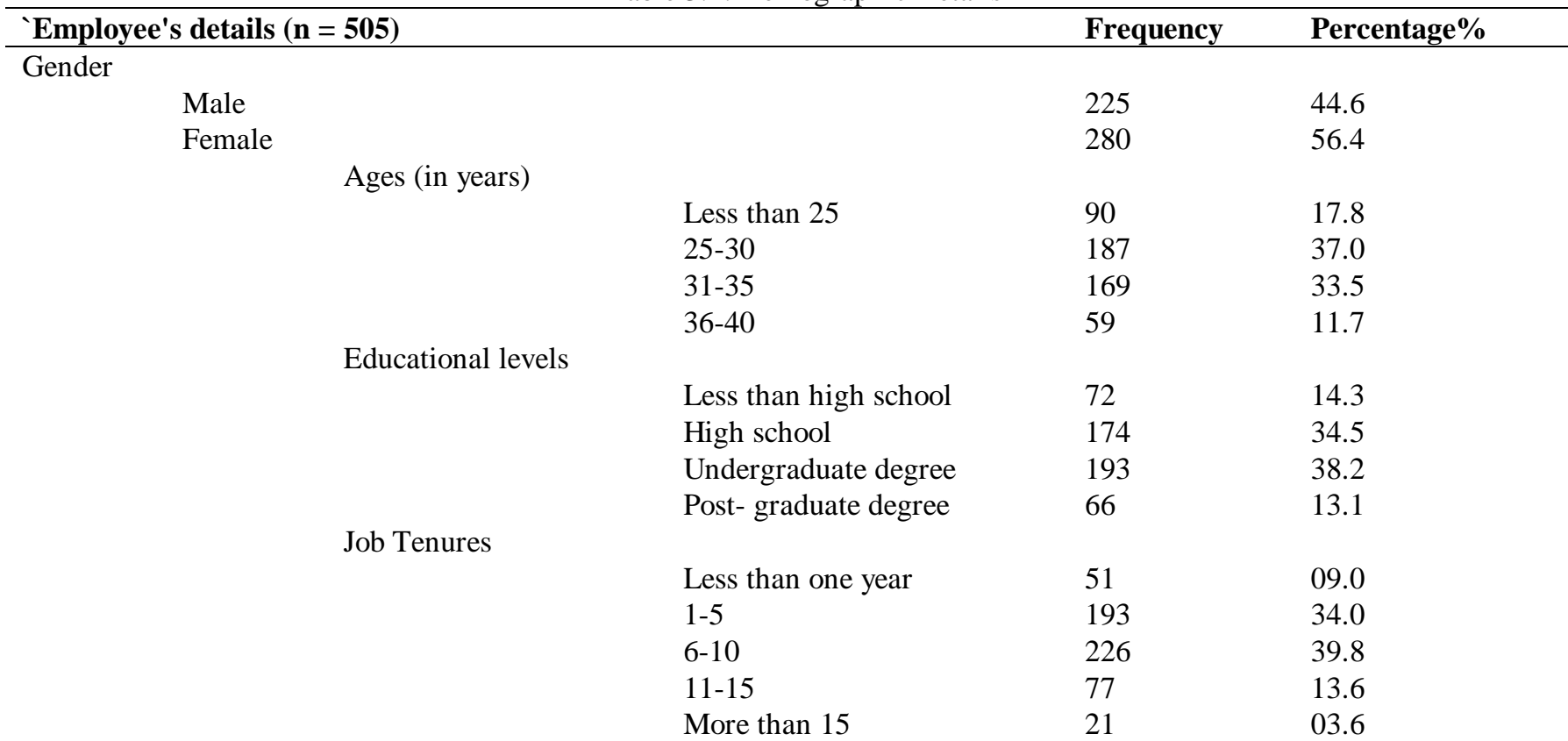

In terms of ages group, most of the participants of the employees and costumers surveyed, fail between 169 frequencies ranging from 25 to 30 years old and 187 frequencies ranging from 31 to 35 years old. the remaining respondents were 90 frequencies which was less than 25 years of age group and 59 frequencies which was from 36 to 40 age group. as presented in the table above (see: table 4.1 ), $17.8 \%$ of the respondents were aged less than $25,37.0 \%$ were aged between 25 years and 35 years, and $33.5 \%$ of the respondents were aged between 31 and 35 . Finally, $11.7 \%$ of the respondents were aged between years 36 and 40 years. The educational levels of the employees have been assessed based on some levels of frequencies assessments. the assessments of the frequencies were based on less than high school to post graduate degree levels of assessments. there have been 72 frequencies assessed for the less than high school levels. for the high school levels, there have been 174 frequencies. for the undergraduate degree levels, there have been frequencies of 193. for the post graduate degree levels, the have been 66 frequencies. In terms of percentages, the educational levels of the employees' frequencies assessments yield different percentages too. For the less than high school groups, the percentage of the frequencies have been recorded as $14.3 \%$. for the high school groups, the percentages of the frequencies have been recorded as $34.5 \%$. for the undergraduate degree groups, the percentage of the frequencies haven seen to be $38.2 \%$. for the post graduate degree levels, the percentage of the frequencies have also been recorded to be $13.1 \%$.

The job tenure for the less than high school groups showed frequencies of 51 times that happened within less than one-year. for the high school groups, it showed frequencies of 193 times happening within 1 to 5 years. for the

undergraduate degree groups, it showed frequencies of 226 times happening within 6 to 10 years. for the post graduate degree groups, it showed frequencies of 77 times happening within 11 to 15 years. for the post graduate degree groups, it showed frequencies of more than 15 times happening within 21years. In terms of percentages, the job tenure for the less than high school groups showed frequencies of 51 times that happened within less than one-year is $9 \%$. For the high school groups, it showed frequencies of 193 times happening within 1 to 5 years 34\%. For the undergraduate degree groups, it showed frequencies of 226 times happening within 6 to 10 years is close to $40 \%$. For the post graduate degree groups, it showed frequencies of 77 times happening within 11 to 15 years is About 14\%. For the post graduate degree groups, it showed frequencies of more than 15 times happening within 21 years is about $4 \%$.

\section{A. Model specification}

For the current study the variables that used to formulate the hypotheses statements were perceived accessibility to training, perceived benefits from training, and perceived support for training. The factors that helped develop the conceptual model has been derived from the existing literature. the hypothesis formulations were based on study of the hypothetical relationships evaluations of the factors that had been used in the literature mentioned (see: section and three) above. The diagram below shows how perceived accessibility to training, perceived benefits from training, and perceived support for training are conceptually related. 


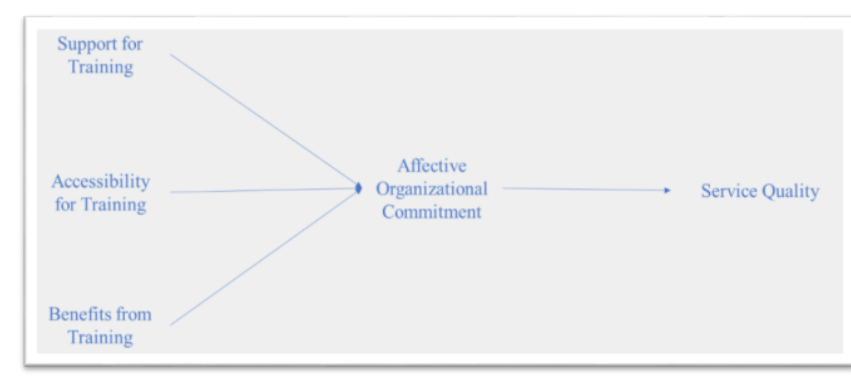

Fig. 3.1 Conceptual model

The diagram above shows the direct relationships between different perceived trainings and affective organizational commitments. Further the diagram also shows the direct relationship between affective organizational commitment and service quality. Therefore, affective organizational commitment plays a central role between the different perceived trainings and service quality. Thus, due to this central role of affective organizational commitment, indirect relationships between the different perceived trainings and service quality is expected. As a result, the study not only will test the direct effects of the relationships but also the indirect effects of the relationships. In the following section the empirical results and analysis of the study discussed.

\section{EMPIRICAl RESUlts AND DATA ANALysis}

In this section, the research result is presented. first the descriptive statistics and correlation of the study is presented and described. second the results of the direct and the indirect Table 4.1: Means, Standard Deviations (SD), Correlations, Squared Correlations and Average Variance Explained (AVE) of Constructs.

\begin{tabular}{|c|c|c|c|c|c|c|c|c|c|}
\hline & & & & & & Correla & ons of & tructs & \\
\hline Constructs & $\mathrm{CR}$ & Means & $\mathrm{SD}$ & AVE & AT & SQ & $\mathrm{AOC}$ & ST & BT \\
\hline Accessibility to Training & 0.83 & 3.195 & 1.194 & 0.62 & $(0.79)$ & & & & \\
\hline Service Quality & 0.90 & 3.015 & 1.141 & 0.63 & 0.36 & $(0.80)$ & & & \\
\hline $\begin{array}{l}\text { Affective Organizational } \\
\text { Commitment }\end{array}$ & 0.88 & 3.09 & 1.112 & 0.55 & 0.37 & 0.60 & $(0.74)$ & & \\
\hline Support for Training & 0.90 & 3.03 & 1.179 & 0.60 & 0.35 & 0.31 & 0.27 & $(0.78)$ & \\
\hline Benefits from Training & 0.79 & 3.087 & 1.118 & 0.57 & 0.42 & 0.34 & 0.45 & 0.47 & $(0.75)$ \\
\hline
\end{tabular}
$\mathrm{BT}=$ Benefits from training. Diagonal values are all higher than the correlations between target constructs without exception. $* \mathrm{p}<.05 . * * \mathrm{p}<0.01$

As shown in the table (see: the table above), the correlations between the factors are ranging from 0.0 .45 to 0.35 and are smaller than the square root of the average variance extracted estimates which are in the range of 0.47 to 0.36 . This indicates that the variables are strongly related to their respective indicators compared to other variables of the model [1]. From the view point of the standard deviations of all the items, the data show enough variation to represent the population. The means of the items suggest that the respondents had a moderate attitude toward supervisor support for training, access to training and benefits from training (mean $=3.03,3.195$, and 3.09 respectively). Respondents generally agreed that affective organizational commitment (mean $=3.09$ ) is slightly acceptable. It could be thought that respondents positively perceived service quality of the units as essential (mean = 3.02) toward the neutral point 2.5. This means that the institutional perceptions of access to training, support for training, and benefits from

training of affective organizational commitment on service quality of the units (licensed units) are reasonably acceptable

\section{B. Measurement model}

The measurement for service quality is comprised of five models derived from access to training, support for training, benefits from training, and affective organizational commitment that affect service quality. Therefore, there are five models that can explain service quality. the first model is model 1 which is constructed based on five factors that includes tangibles, reliability, responsiveness, assurance and empathy is concerned with affective organizational commitments and service quality. the second is model 2 which is constructed based on four factors in which responsiveness and tangibles are merged as one factor. the third is model 3 which constructed based on four factors in which reliability and empathy are merged as one factor. The fourth is model 4 which is constructed 
Examining the Accessibility, Support, Benefits of Training in Road and Transport Authority: The Case of Service Quality in UAE

based on three factors in which tangibles, reliability and responsiveness are merged as one construct. the fifth is model 5 which is constructed based on all the constructs combined merged as one factor. Table 4.5 showed the five models. Confirmatory factor analysis.

Table 4.2: Confirmatory factor analysis

\begin{tabular}{lllllll}
\hline Model fitness & $\chi 2$ & $\mathrm{~d} f$ & AGFI & NFI & CFI & RMSEA \\
\hline Model I & 511.669 & 204 & 0.90 & 0.92 & 0.95 & 0.055 \\
Model II & 642.176 & 205 & 0.86 & 0.90 & 0.93 & 0.065 \\
Model III & 966.853 & 205 & 0.76 & 0.85 & 0.88 & 0.086 \\
Model IV & 859.010 & 205 & 0.80 & 0.87 & 0.89 & 0.080 \\
Model V & 1349.979 & 206 & 0.67 & 0.80 & 0.82 & 0.105 \\
Model VI & 2051.616 & 209 & 0.58 & 0.69 & 0.71 & 0.130 \\
\hline
\end{tabular}

As shown in the table, Confirmatory factor analysis (CFA) has been performed to identify the measurement models for the study and determine the fitness of models. Model I which is concerned with service quality is based on five variables; which includes tangibles, reliability, responsiveness, assurance and empathy. The model fits the data as shown by the result of the analysis $(\chi 2=511.669$, df $=204, \mathrm{p}<.01 ; \chi 2 / \mathrm{df}=2.50 \mathrm{AGFI}=0.90 ; \mathrm{CFI}=0.95 ; \mathrm{NFI}$ $=0.92$, RMSEA $=0.05$ ).

Model II includes reliability, assurance and empathy separately, but responsiveness and tangibles were merged. The results showed a good fit for the Model $(\chi 2=642.176$, $\mathrm{df}=205, \mathrm{p}<.01 ; \chi 2 / \mathrm{df}=3.13$ AGFI $=0.86 ; \mathrm{CFI}=0.93$; $\mathrm{NFI}=0.90$, RMSEA $=0.06$ ). however, model II is less in fitness than Model I in which all items loaded on their intended constructs. Model III has been computed based on four factors that includes reliability and empathy merged as one factor. The model fits the data it showed a good fit to the model $(\chi 2=966.852, \mathrm{df}=205, \mathrm{p}<.01 ; \chi 2 / \mathrm{df}=4.72$ AGFI $=0.77$; CFI $=0.88 ; \mathrm{NFI}=0.85$, RMSEA $=0.09$ ). however, the model is also less in fitness when compared to model I. Model IV has been based on two factors which combined the items representing empathy and assurance that have merged as one construct. However, the model yielded a poorer fit to the data than the other models $(\chi 2=859.010, \mathrm{df}=205, \mathrm{p}<$ $.01 ; \chi 2 / \mathrm{df}=4.20, \mathrm{AGFI}=0.80 ; \mathrm{CFI}=0.90 ; \mathrm{NFI}=0.87$, RMSEA $=0.08$ ). model $\mathrm{V}$ has been based on three factors which includes tangibles, reliability and responsiveness that have been merged as one construct. This model also yielded a poorer fit to the data than the other model of the study $(\chi 2$ $=1349.979, \mathrm{df}=206, \mathrm{p}<.01 ; \chi 2 / \mathrm{df}=6.55, \mathrm{AGFI}=0.67$;
$\mathrm{CFI}=0.82 ; \mathrm{NFI}=0.80, \mathrm{RMSEA}=0.105)$. Finally model VI has been based on one factor model, in which all items of the research have constructed to load on a single factor. The result shows as follows $(\chi 2=2051.616, \mathrm{df}=209, \mathrm{p}<.01 ; \chi 2 /$ $\mathrm{df}=9.82, \mathrm{AGFI}=0.58 ; \mathrm{CFI}=0.71 ; \mathrm{NFI}=0.69, \mathrm{RMSEA}=$ 0.13 . Out all models that have just been discussed, model 1 which had been based five variables (a five-factor model) best fits the data of the study. The result supported the discriminant validity of each variable and is consistent with past studies example.

The overall model fitness indicators of the study showed that AGFI, NFI, CFI, RMSEA and other indicators are fit. The Absolute fit indices show that the chi-square is significant ( $p$ value $>0.5$ ). the chi-square is significant, the model fits. Therefore, the properties of the measurement model could now be evaluated in terms of constructs and indicators of reliability, convergent and discriminant validity.

\section{a. Reliability}

Reliability relates to the consistency of a measure. "A participant completing an instrument meant to measure motivation should have approximately the same responses each time the test is completed". Cronbach's alpha (see: table 4.2) was used to measure the internal consistency of the multi-item scales adopted for current study. the values of Cronbach's alpha for all the study variables were above 0.70 . The Cronbach's alpha values for the study variables are from 0.85 to 0.95 , indicating that all the variables are reliable. The entire study variables were adopted from prior studies and all the study variables are reliable and achieved high validity.

Table 4.3. Means, Standard Deviations, and Reliability of Constructs

\begin{tabular}{|c|c|c|c|c|}
\hline Constructs & & Mean & $S D$ & $\alpha$ \\
\hline \multicolumn{5}{|l|}{ Service Quality } \\
\hline \multirow[t]{11}{*}{ Tangibles } & & & & 0.84 \\
\hline & $\mathrm{Tt} 1$ & 3.075 & 1.2576 & \\
\hline & $\mathrm{Tt} 2$ & 3.030 & 1.2508 & \\
\hline & $\mathrm{Tt} 3$ & 3.004 & 1.2646 & \\
\hline & $\mathrm{Tt} 4$ & 3.020 & 1.2502 & \\
\hline & & & & 0.89 \\
\hline & RL1 & 3.077 & 1.1198 & \\
\hline & RL2 & 3.111 & 1.1196 & \\
\hline & RL3 & 3.077 & 1.1216 & \\
\hline & RL4 & 3.095 & 1.1211 & \\
\hline & RL5 & 3.101 & 1.1303 & \\
\hline
\end{tabular}




\begin{tabular}{|c|c|c|c|c|}
\hline \multirow[t]{5}{*}{ Responsiveness } & & & & 0.85 \\
\hline & RS1 & 3.036 & 1.1997 & \\
\hline & $\mathrm{RS} 2$ & 3.063 & 1.1885 & \\
\hline & RS3 & 3.030 & 1.1973 & \\
\hline & RS4 & 3.067 & 1.1933 & \\
\hline \multirow[t]{5}{*}{ Assurance } & & & & 0.85 \\
\hline & AS1 & 3.234 & 1.2332 & \\
\hline & AS2 & 3.226 & 1.2411 & \\
\hline & AS3 & 3.216 & 1.2340 & \\
\hline & AS4 & 3.228 & 1.2447 & \\
\hline \multirow[t]{6}{*}{ Empathy } & & & & 0.88 \\
\hline & EM1 & 3.129 & 1.2171 & \\
\hline & EM2 & 3.141 & 1.2272 & \\
\hline & EM3 & 3.145 & 1.2202 & \\
\hline & EM4 & 3.141 & 1.2174 & \\
\hline & EM5 & 3.131 & 1.2210 & \\
\hline \multirow[t]{4}{*}{ Access to training } & & & & 0.83 \\
\hline & AT1 & 3.2931 & 1.22038 & \\
\hline & AT2 & 3.2950 & 1.21420 & \\
\hline & AT3 & 3.2812 & 1.21014 & \\
\hline \multicolumn{5}{|l|}{ Affective Organizational Commitment } \\
\hline & & & & 0.88 \\
\hline & $\mathrm{OC} 1$ & 3.0891 & 1.11001 & \\
\hline & $\mathrm{OC} 2$ & 3.0990 & 1.11541 & \\
\hline & OC3 & 3.0990 & 1.11185 & \\
\hline & OC4 & 3.0911 & 1.12141 & \\
\hline & OC5 & 3.0950 & 1.12285 & \\
\hline & OC6 & 3.0891 & 1.12068 & \\
\hline \multicolumn{5}{|l|}{ Benefits from Training } \\
\hline \multirow[t]{6}{*}{ Personal-related benefits of training } & & & & 0.87 \\
\hline & BP1 & 3.0772 & 1.12157 & \\
\hline & BP2 & 3.1109 & 1.12139 & \\
\hline & BP3 & 3.0931 & 1.11326 & \\
\hline & BP4 & 3.1129 & 1.10605 & \\
\hline & BP5 & 3.1030 & 1.12392 & \\
\hline \multirow[t]{6}{*}{ Career-related benefits of training } & & & & 0.88 \\
\hline & $\mathrm{BC} 1$ & 3.0772 & 1.13038 & \\
\hline & $\mathrm{BC} 2$ & 3.0871 & 1.11995 & \\
\hline & BC3 & 3.0871 & 1.11818 & \\
\hline & $\mathrm{BC} 4$ & 3.0891 & 1.11891 & \\
\hline & BC5 & 3.0891 & 1.11891 & \\
\hline \multirow[t]{3}{*}{ Job-related benefits of training } & & & & 0.81 \\
\hline & $\mathrm{BJ} 1$ & 3.0891 & 1.11891 & \\
\hline & $\mathrm{BJ} 2$ & 3.0891 & 1.17090 & \\
\hline \multirow[t]{7}{*}{ Support for training } & & & & 0.90 \\
\hline & ST1 & 3.0376 & 1.18714 & \\
\hline & ST2 & 3.0218 & 1.18920 & \\
\hline & ST3 & 3.0337 & 1.19059 & \\
\hline & ST4 & 3.0594 & 1.18541 & \\
\hline & ST5 & 3.0257 & 1.18243 & \\
\hline & ST6 & 3.0436 & 1.17264 & \\
\hline
\end{tabular}

Items of each construct were evaluated by means of Cronbach's alpha including item-to-total correlations (ITTC), and "confirmatory factor analysis" (CFA) as just discussed. The values of the Cronbach's alpha for accessibility to training is 0.83 . the value of the Cronbach's alpha for support for training is 0.90. the value of the Cronbach's alpha for affective organizational commitment is 0.88. further, the value of the Cronbach's alpha for personal-related benefits of training is 0.87 , the value of the Cronbach's alpha for Career-related benefits of training is 0.88 , and the value of the Cronbach's alpha for Job-related benefits of training is 0.81 . furthermore, the value of the Cronbach's alpha for tangibles is 0.84 . the value of the Cronbach's alpha for reliability is 0.89 , the value of the Cronbach's alpha for responsiveness is 0.85 . 
the value of the Cronbach's alpha for assurances is 0.85 . in addition, the value of the Cronbach alpha for empathy is 0.88 that revealed the high reliability of the factors under examination.

As revealed, all constructs are also in line with exceeding the square of the correlations between pairwise matched factors (Fornell and Larcker, 1981). The alpha coefficients of variables ranged from 0.83 to 0.90 , which satisfied the minimum threshold value of 0.70 . As recommended in previous research (Fornell and Larcker, 1981), "discriminant validity" was also assessed by comparing AVE values and squared correlations between constructs.

\section{Tests of Direct Relationships between Trainings and Service Quality}

The hypotheses of this study were tested using structural equation modelling via AMOS. Results of the analysis of the test for direct relationships between trainings and service quality consisting of seven hypotheses is presented in table 4.5 and the indirect hypothesis tests are provided in table 4.6. Moreover, all hypotheses are supported. Table 4.6 presented the analytical results of the direct relationships between perceived trainings and affective organizational commitments, perceived trainings and service quality, as well as affective organizational commitment and service quality consisting of the seven hypotheses

Table 4.5: Direct relationships

\begin{tabular}{|c|c|c|c|c|c|c|c|}
\hline & \multirow[t]{2}{*}{ Hypotheses } & \multirow[t]{2}{*}{$\beta$} & \multirow[t]{2}{*}{ S. E } & \multirow[t]{2}{*}{ t-value } & \multicolumn{2}{|c|}{$\begin{array}{l}95 \% \\
\text { confidence }\end{array}$} & \multirow[t]{2}{*}{ Results } \\
\hline & & & & & Lower & Upper & \\
\hline H1 & $\begin{array}{l}\text { Support for Training to Affective Organizational } \\
\text { Commitment }\end{array}$ & 0.26 & 0.056 & $4.64 *$ & 0.19 & 0.29 & Supported \\
\hline $\mathrm{H} 2$ & $\begin{array}{l}\text { Access to Training to Affective Organizational } \\
\text { Commitment }\end{array}$ & 0.33 & 0.045 & $7.33 * *$ & 0.29 & 0.35 & Supported \\
\hline H3 & $\begin{array}{l}\text { Benefits from Training to Affective Organizational } \\
\text { Commitment }\end{array}$ & 0.47 & 0.034 & $\begin{array}{l}13.82 * \\
*\end{array}$ & 0.41 & 0.50 & Supported \\
\hline $\mathrm{H} 4$ & Support for Training to Service Quality & 0.32 & 0.044 & $7.27 * *$ & 0.28 & 0.35 & Supported \\
\hline H5 & Accessibility to Training to Service Quality & 0.33 & 0.044 & $7,50 * *$ & 0.28 & 0.37 & Supported \\
\hline H6 & Benefits from Training to Service Quality & 0.38 & 0.055 & $6.90 * *$ & 0.33 & 0.41 & Supported \\
\hline $\mathrm{H} 7$ & $\begin{array}{l}\text { Affective Organizational Commitment to Service } \\
\text { Quality }\end{array}$ & 0.57 & 0.035 & $\begin{array}{l}16.29 * \\
*\end{array}$ & 0.51 & 0.59 & Supported \\
\hline
\end{tabular}

Hypothesis 1 stated that support for training has a positive affect affective organizational commitment. The test result indicates that support for training has positively and significantly affect affective organizational commitment $(\beta$ $=0,26, \mathrm{t}=4.64, \mathrm{p}<0.05)$. This result supported the hypothesis testing and the finding is consistent with previous works. Hypothesis 2 stated that accessibility to training has a positively affect affective organizational commitment. the result of the research of the study indicated that accessibility to training has a positive and significant effect on affective organizational commitment $(\beta=0.33, \mathrm{t}=$ $7.33, \mathrm{p}<0.01)$. the result of the study is consistent with result studies of previous works.

Hypothesis 3 reported that 'employees' perception of benefits from training has a positive effect on employees' affective organizational commitment. The results in Table 6 indicate that the path from benefits from training to affective organizational commitment is positive and significant $(\beta$ $=0.47, \mathrm{t}=13.82 . \mathrm{p}<0.01)$. This result supported hypothesis test and consistent with the study of previous works. Hypothesis 4 states that employees' perception of support for training has a positive effect on customer service quality. In Table 6 the results indicate that the regression from support for training to customer service quality is positive and significant $(\beta=0.32, \mathrm{t}=7.27, \mathrm{p}<0.001)$. This result is supported and is consistent with results of previous works which revealed that access to training, support for training and benefits from training had positive influence on service quality. Hypothesis 5 states that employees' perception of access to training has a positive effect on customer service quality. The Table 6 indicates that access to training has a positive significant influence on service quality $(\beta=0.33, \mathrm{t}$ $=7.50, \mathrm{p}<0.001)$. This result supported Hypothesis. The results regarding Hypotheses 5, 6 and 7 agree with the findings of previous works which revealed that access to training, support for training and benefits from training had positive influence on service quality.

Hypothesis 6 states that employees' perception of benefits from training has a positive effect on customer service quality. The Table 6 indicates that benefits from training has a positive significant influence on service quality $(\beta=0.38$, $\mathrm{t}=6.91, \mathrm{p}<0.001)$. This result supported Hypothesis. The results regarding Hypotheses 5, 6 and 7 agree with the previous works which revealed that access to training, support for training and benefits from training had positive influence on service quality. Hypothesis 7 states that affective organizational commitment has a positive effect on customer service quality". The Table 6 indicates that benefits from training has a positive significant influence on service quality $(\beta=0.57, \mathrm{t}=16.29, \mathrm{p}<0.01)$. This result supported Hypothesis. The results regarding Hypotheses 5 , 6 and 7 agree with the findings of previous works which revealed that access to training, support for training and benefits from training had positive influence on service quality. 


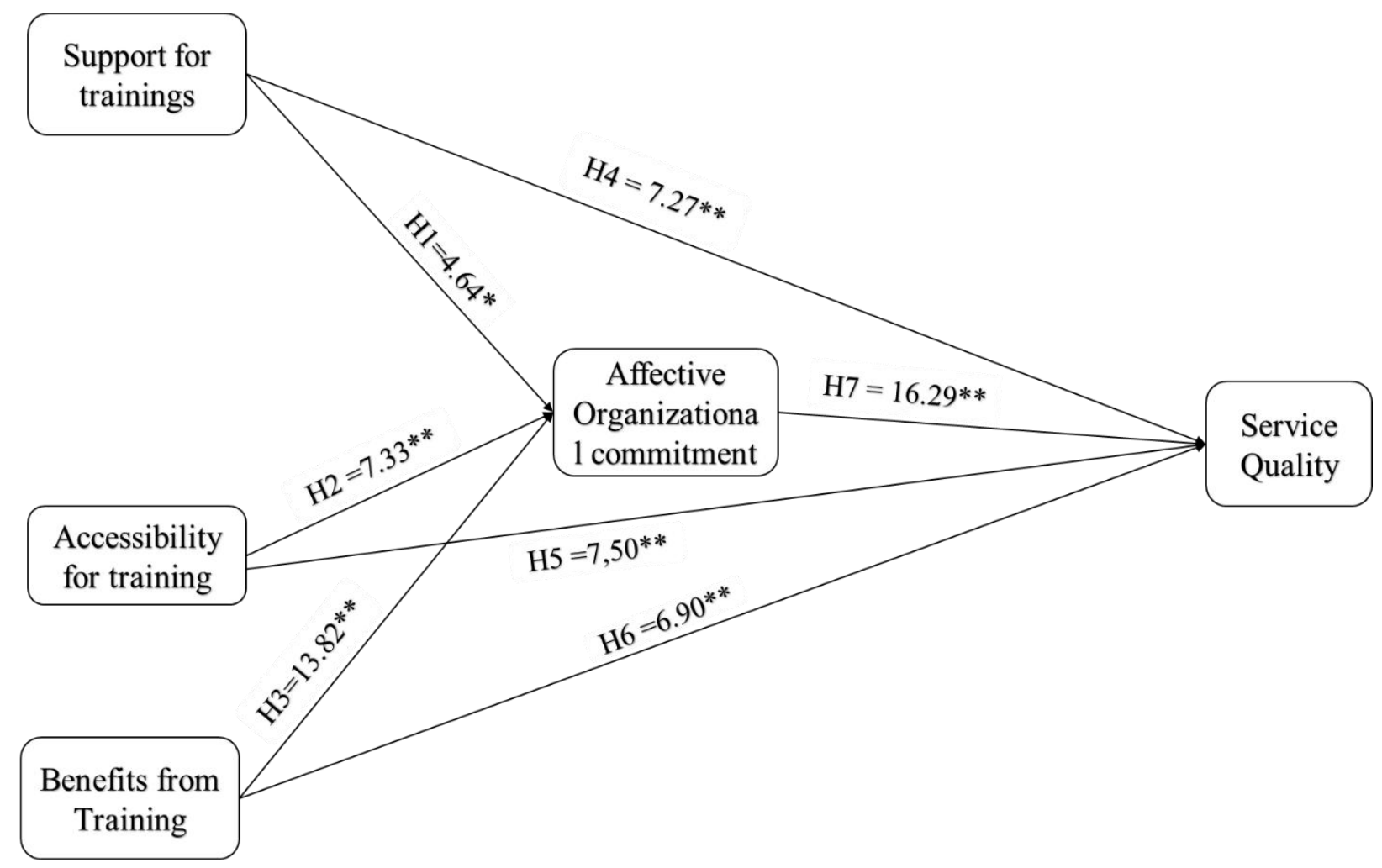

Fig. 3.1 result model

\section{a. Tests of Indirect Relationships between trainings and} service quality

In this section, three hypotheses of testing are discussed. The three hypotheses testing have indirect implications of the study. The study adopted the four steps as specified in the literature. the study also used a nonparametric resampling

procedure (Bootstrapping) as an additional mediating test following. Results of the analysis of the test for indirect relationships between trainings and service quality consisting of the three hypotheses is presented in table 4.6. Table 4.6: Analysis Result of Indirect Relationships trainings and service quality

\begin{tabular}{|c|c|c|c|c|c|c|c|}
\hline & \multirow[t]{2}{*}{ Hypotheses Paths } & \multirow[t]{2}{*}{$\beta$} & \multirow[t]{2}{*}{ S. E } & \multirow[t]{2}{*}{ t-value } & \multicolumn{2}{|c|}{$95 \%$ confidence } & \multirow[t]{2}{*}{ Results } \\
\hline & & & & & Lower & Upper & \\
\hline \multirow[t]{3}{*}{ H8 } & From Access to Training to service quality via & 0.22 & 0.024 & 9.20 & 0.13 & 0.22 & Supported \\
\hline & Affective Organizational Commitment & & & & & & \\
\hline & $\begin{array}{l}\text { From Access to Training to service quality controlling } \\
\text { Affective Organizational Commitment }\end{array}$ & 0.17 & 0.042 & 4.05 & 0.08 & 0.24 & \\
\hline \multirow[t]{2}{*}{ H9 } & $\begin{array}{l}\text { From Support for Training to service quality via } \\
\text { Affective Organizational Commitment }\end{array}$ & 0.14 & 0.024 & 5.83 & 0.09 & 0.19 & Supported \\
\hline & $\begin{array}{l}\text { From Support for Training to service quality } \\
\text { controlling Affective Organizational Commitment }\end{array}$ & 0.19 & 0.041 & 4.63 & 0.10 & 0.26 & \\
\hline \multirow[t]{2}{*}{ H10 } & $\begin{array}{l}\text { From Benefits for Training to service quality via } \\
\text { Affective Organizational Commitment }\end{array}$ & 0.24 & 0.031 & 7.74 & 0.001 & 0.19 & Supported \\
\hline & $\begin{array}{l}\text { From Support for Training to service quality } \\
\text { controlling Affective Organizational Commitment }\end{array}$ & 0.14 & 0.059 & 2.37 & 0.020 & 0.25 & \\
\hline
\end{tabular}

Hypothesis 8 mentions that affective organizational commitment mediates the relationship between access to training and service quality. The mediating implications of affective organizational commitment were measured by using AMOS: affective organizational commitment mediates the relationship between access to training and service quality (See: hypothesis 5). The study adopted the four steps specifications as specified by previous research works and used a nonparametric resampling procedure (Bootstrapping) as an additional mediating test following. To meet the four steps specifications, the results of $\mathrm{H} 1, \mathrm{H} 3$ and $\mathrm{H} 4$ must first be supported (See: section 4.3); the first step the paths from accessibility to training (independent variable) to service quality (dependent variable) is significant $(\beta=0.33, \mathrm{t}=7.50$, $\mathrm{p}<0.05)$. The second step, the paths from accessibility to training as an explanatory variable to affective organizational commitment as a mediating variable is significant. $(\beta=0.33, \mathrm{t}=7.33, \mathrm{p}<0.01)$. The third step, the paths from affective organizational commitment as a mediating variable to service quality as response variable is significant. $(\beta=0.57, \mathrm{t}=16.29, \mathrm{p}<$

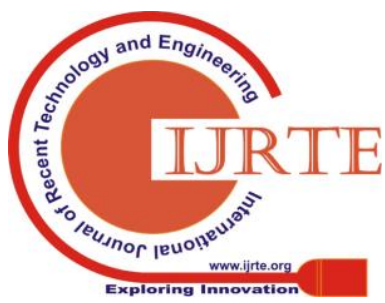


0.01. The first three steps specified are supported. Therefore, the indirect link from accessibility to training (independent variable) to service quality (dependent variable) via affective organizational commitment (mediating variable) is significant $(\beta=0.22, t=9.20, p<0.01)$. the Bootstrap values does not include zero $[0.13 ; 0.22]$. While the direct effect of accessibility to training on service quality after controlling for affective organizational commitment as mediating factor is insignificant $(\beta=0.17, \mathrm{t}=4.05, \mathrm{p}<0.05)$, the Bootstrap values does not include zero [0.08; 0.24] see table 4.6. According to these results, Hypothesis 7 is supported, and the mediating effect of affective organizational commitment is partial mediation

Hypothesis 9 states that affective organizational commitment mediates the relationship between support for training and service quality. The mediating effects of affective organizational commitment have been measured by using AMOS. The study adopted the four steps as specified previous works, and the Bootstrapping was tested. To meet the four steps of previous works, the results first must support hypotheses 1,2 and 7 as shown in the previous results (See: section 4.3). The first step is the acknowledgement of the significant relationship that exists between support for training and service quality because the paths from support for training as an independent variable to service quality as a dependent variable is significant $(\beta=0.32, \mathrm{t}=7.27, \mathrm{P}<$ 0.001) (See: H4 in table 4.6). The second step is the acknowledgement of the significant relationship that exists between support for training and affective organizational commitment because the paths from support for training as an independent variable to affective organizational commitment as a mediating variable is significant $(\beta=0.26$, $\mathrm{t}=4.64, \mathrm{P}<0.05$ ) (See: H1 in table 4.6). The third step is the acknowledgement of the significant relationship that exists between affective organizational commitment and service quality because the paths from affective organizational commitment as a mediating variable to service quality as a dependent variable is significant $(\beta=0.57, \mathrm{t}=16.29, \mathrm{P}<$ 0.01 See: $\mathrm{H} 7$ in table 4.6). These first three steps were supported (see Table 4.6). therefore, the indirect link from support for training (independent variable) to service quality (dependent variable) via affective organizational commitment (mediating variable) is significant $(\beta=0.14, \mathrm{t}=$ $5.83, \mathrm{p}<0.01)$, the Bootstrap values does not include zero $[0.09 ; 0.19]$. While the direct effect of support for training on service quality after controlling for the mediating factor (affective organization commitment) is insignificant ( $\beta=$ $0.19, \mathrm{t}=4.63, \mathrm{p}<0.01)$, the Bootstrap values does not include zero $[0.10 ; 0.26]$ see Table 4.6. According to these results, hypothesis 7 is supported the mediating effect of affective organizational commitment is partial.

Hypothesis 10 states that affective organizational commitment mediates the relationship between benefits from training and service quality. The mediating effect has been measured by using AMOS. The study adopted the four steps specifications as specified in previous works, and Bootstrapping test. To meet the four steps specifications of previous research works, the results first have to support Hypotheses 3, 6 and 7 (see the previous section 4.6.2). the first step the paths from benefits from training (independent variable) to service quality (dependent variable) is significant $(\beta=0.38, t=6.91, P<0.001)$ (see: H6). The second step, the paths from benefits from training (independent variable) to affective organizational commitment (mediating variable) is significant $(\beta=0.47, \mathrm{t}=13.82, \mathrm{P}<0.01)$ (See: H3). The third step, the paths from affective organizational commitment to service quality (dependent variable) is significant $(\beta=0.57, \mathrm{t}=16.29, \mathrm{P}<0.01)$ (See: $\mathrm{H} 7)$. These first three steps are supported. therefore, the indirect link from benefits for training (independent variable) to service quality (dependent variable) via affective organizational commitment (mediating variable) is significant $(\beta=0.24, \mathrm{t}=$ $7.74 \mathrm{P}<0.001)$, the Bootstrap values does not include zero $[0.001 ; 0.19]$. While the direct effect of benefits from training on service quality after controlling the mediator (AOC) is insignificant $(\beta=0.14, \mathrm{t}=2.37, \mathrm{p}<0.01)$, the Bootstrap values does not include zero [0.001; 0.19] (See: table 4.6). According to these results, hypothesis 7 is supported and the mediating effect is in fact a partial mediating effect.

\section{Discussion}

\section{A. Discussion}

The main objective of the current study was to investigate the impact of organizational commitment on training for road and transport service quality (See: section 1). More specifically, the objective of the study was to investigate the impact of affective organizational commitment on the relationship between perceived organizational trainings of employees and service quality within the public sectors of United Arab Emirates (UAE). The empirical result showed that there is a significant relationship between organizational training patterns and service quality. The proposed model was tested, which indicated the positive effects of accessibility to training, support for training, and benefits of training on service quality after controlling for affective organizational commitment within the United Arab Emirates (UAE) Public Sectors.

Findings related to objective 1: the first objective of the current study was to investigate the effect of perceived support for training on service quality. The study found that previewed accessibility to training has a positive effect on service quality. This objective was achieved by testing the hypothesis formulated H9. This study showed that affective organizational commitment plays a mediating role between support for training and service quality and it have a positive effect on the relationship. This result is consistent with past studies who claimed that employees who believe that by attending a training program they will gain positive results aspire for and are highly motivated to attend.

Findings related to objective 2: the second objective of the current study was to investigate the effect of previewed accessibility to training on service quality. The study found that previewed accessibility to training has a positive effect on service quality. This objective was achieved by testing the hypothesis formulated, which states that accessibility to training positively affect service quality. This study also showed that affective organizational commitment plays a mediating role between previewed accessibility for training and service quality and it have a positive effect on the relationship. The result of the

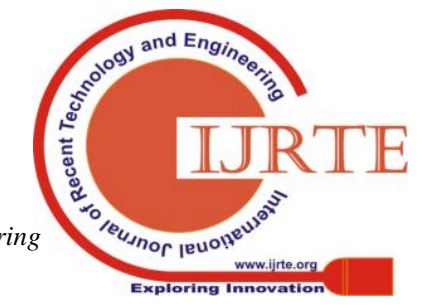


current study is consistent with result of past researches which have reveal that employees who understand the advantages of attending a training program would display a higher level of commitment toward their organization so that they would be allowed to participate in more training activities carried out by the organization.

Findings related to objective 3 : the third objective of the current study was to investigate the effect of perceived benefits from training on service quality. The current study found that perceived benefits from training has a positive effect on service quality This study also showed that affective organizational commitment plays a mediating role between benefits from training and service quality and it have a positive effect on the relationship. This result is consistent with past results of studies who found a strong relationship between the benefits of training programs and affective organizational commitment.

\section{B. Implication for Research and Practice}

The research of this study adds empirical model to the literature in the field organizational behaviour. this study is the first of its kind in the public sectors of UAE, which investigated the three variables as main organization patterns. This study incorporates three-second order constructs; accessibility to training, support for training, and benefits of training (as independent variables) to explain service quality (as a dependent variable) using affective organizational commitment (as mediating variable) in one research model. The findings of this study showed that affective organizational commitment mediates the relationship between accessibility to training, and support for training, as well as benefits of training and service quality.

This study underpins the main issues in our understanding of the role of accessibility to training, and the role of support for training, as well as the role of benefits of training and the role of affective organizational commitment in evaluating service quality across UAE public sectors. As anticipated, accessibility to training, support for training, and benefits of training have positive effects on service quality, in both with integrating affective organizational commitment as mediating variable, or without integrating affective organizational commitment as mediating variable.

This study helps in disclosing the ways in which accessibility to training, and support for training, as well as benefits of training can complement the service quality by exhibiting the importance of affective organizational commitment as mediating variable. By adopting accessibility to training, support for training, and benefits of training, it helps in developing affective organizational commitment among public employees, which will result in increasing service quality of the public sector of UAE. The reason for this is that as indicated above, accessibility to training, support for training, and benefits of training positively affect the affective organizational commitment. and affective organizational commitment of employees of public sectors will enhance service quality. However, this can happen if organizations promote affective organizational commitment among their employees. This research finding indicates affective organizational commitment as mediating variable have partial effect on the relationship between accessibility to training, and support for training, as well as benefits of training and service quality, which means that there are other factors which have an impact on trainings and service quality relationships

\section{LIMITATIONS AND SUGGESTIONS FOR FUTURE WORK}

The present study has several limitations. This study only measures the relationships between accessibility to training, support for training, and benefits of training on one hand and affective organizational commitment on the other to explain public sectors of service quality. Based on the result of this study, the future research can use this study as a reference for applying method of service quality in broader terms. For example, future research can use numerous organizational patterns of service quality other than perceived trainings. Empirically, it is found that there is a significant relationship between organizational pattern of service quality and the sales-based performance of organizations. Profitability, growth, productivity, level of sales revenue, market share and product, return on investments, product added value is used in the measurement of Sales-based performance. In addition, other previous studies have also further illustrated that there is a significant relationship between competitive advantage and firm-based performance of organizations. Firm-based performance is measured in terms of the emphasis on employee development, customer satisfaction, job satisfaction and efficient organizational internal processes. Data compilation method is also considered one of the limitations, since questionnaire method was the only technique used in the data gathering procedures. Therefore, it is suggested that future research should assemble data using multiple techniques. Furthermore, this study focused on public sectors of licensed units in UAE and targeted all front-line employees as well as randomly selected three customers for each employee to participate in the questionnaires. There implication with private sector too. Therefor future research should also focus on private sector too to explain the implication of training in private sectors. Furthermore, the study has been restricted within the public sector in UAE only. Due to privacy concern involved, respondents might have been reluctant to share correct information due to their defensive attitude. The element of subjectivity might have not been checked completely as respondents have responded based on their own experience and perceptions regarding the statements in the questionnaire. In future, Comparative study between private and public sector can be undertaken. Moreover, outcomes can be considered, for example, cultural differences, other trainings styles, and so on for better understanding of the concept.

\section{CONCLUSION}

Overall, the main goal of this paper was to examine the effects of accessibility to training, support for training, and benefits of training on service quality using affective organizational commitment as mediating variable within the public sector in United Arab Emirates. The objective of this study was to provide empirical findings whether affective organizational commitment affects the relationship between accessibility to training, support for training, and benefits of training and service quality. The sample of the study was public sectors in UAE. The findings in

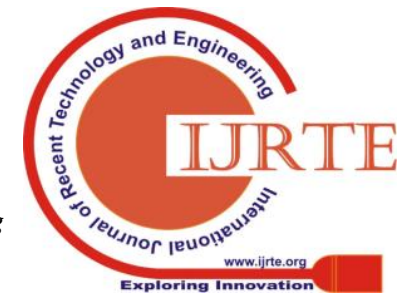


this paper suggest that accessibility to training, support for training, and benefits of training positively affected service quality with or without affective organizational commitment as mediating factor. The results document that affective organizational commitment is positively related to service quality. accessibility to training, support for training, as well

\section{REFERENCES}

[1] C. Fornell \& D. F. Larcker, (1981). Evaluating structural equation models with unobservable variables and measurement error. Journal of Marketing Research, 18(1), pp. 39-50.

\section{AUTHORS PROFILE}

Hamdan ALMATRUSHI profile which contains their education details, their publications, research work, membership, achievements, with photo that will be maximum 200-400 words.

Mohammed NUSARI profile which contains their education details, their publications, research work, membership, achievements, with photo that will be maximum 200-400 words.

Ali Ameen profile which contains their education details, their publications, research work, membership, achievements, with photo that will be maximum 200-400 words.

Amiya Bhaumik profile which contains their education details, their publications, research work, membership, achievements, with photo that will be maximum 200-400 words. as benefits of training and affective organizational commitment of the service sectors contributed positively to the studies of service quality, which suggest that this is an important factor that helps broaden knowledge of service quality in UAE public sectors. 